\title{
PENGARUH PENGGUNAAN GELEMBUNG UDARA SEBAGAI ALAT BANTU JARING LINGKAR BUBU TERHADAP HASIL TANGKAPAN IKAN HIAS
}

\author{
Abdul Malik Tangko"), Abdul Mansyur"), dan Daud Pongsapan")
}

\begin{abstract}
ABSTRAK
Ikan hias laut bernilai ekonomis penting dengan potensi sekitar 5.000 ton atau 30-50 juta ekor per tahun, diperkirakan dapat mencapai 400 jenis. Penggunaan gelembung udara sebagai alat bantu jaring lingkar bubu pada penangkapan ikan hias telah dilakukan di perairan Pulau Podang-Podang. Kabupaten Pangkep, Sulawesi Selatan, pada bulan Maret hingga April 1999. Penelitian ini bertujuan untuk menentukan besaran unit gelembung udara sebagai alat bantu yang efektif pada penangkapan ikan hias dengan jaring lingkar bubu. Jumlah unit gelembung udara yang dijadikan perlakuan yaitu 5 , 10, dan 15 unit. Lama pengoperasian jaring lingkar bubu sebelum hauling atau pengangkatan adalah 30 menit. Hasil penelitian menunjukkan bahwa jumlah unit gelembung udara tidak mempengaruhi jumlah hasil tangkapan $(P>0,05)$. Total hasil tangkapan selama penelitian (15 kali hauling) adalah 1138 ekor dengan perincian: perlakuan gelembung udara 5 unit 268 ekor (rata-rata 18 ekor/haul); 10 unit gelembung udara 395 ekor (rata-rata 26 ekor/haul) dan 15 unit gelembung udara 475 ekor (ratarata 32 ekor/haul). Komposisi jenis ikan hias yang tertangkap terdiri dari famili Pomacentridae, Labridae, Chaetotontidae, Scaridae, dan Mulidae. Jenis spesies ikan yang tertangkap didominansi oleh ikan biru (Chrysiptera spinger), ikan betok hitam (Chrypteera ummaculata), zebra lurik hitam (Damsel pseudochrysopecilus), zebra hitam (Damsel fasciatus), dan zebra hitam (Dascyllus melanurus).
\end{abstract}

\section{ABSTRACT: The effect use of air bubbles as supporting gear of trap seine net for ornamental fish fishing. By : Abdul Malik Tangko, Abdul Mansyur, and Daud Pongsapan}

\begin{abstract}
Marine ornamental fish are important commercial fish, which can reach the production level of 5,000 tons or about $30-50$ million fish per year. These fish can be classified into approximately 400 species. A study was carried out to know the effect of air bubbles used to support trap seine net operation for ormamental-fish fishery. The experiment was conducted in Pulau Podang-Podang Pangkep, Regency of South Sulawesi from March to April 1999. The aim of the research was to know the effectiveness of air bubbles source for ornamental fish fishing with trap seine net. Numbers of airbubbles generating pipes of 5,10, and 15 units per pipe were applied in fishing operation designed as different treatments. The duration of net operation before hauling was 30 minutes. The results of the experiment showed that there was no significant difference $(P>0,05)$ between total catch $(1138$ individuals) of all treatments. Treatment with 5 units of air bubbles resulted in 268 fish caught with an average catch of 18 fishes/haul, treatment with 10 units of air bubbles resulted in 395 fish caught with average catch of 26 fishes/haul, and treatment with 15 units of air bubbles resulted in 475 fish with an average of 32 fishes/haul. The ornamental fish composition was dominated by various families i.e: Pomacentridae, Labridae, Chaetodontidae, Scaridae, and Mullidae. The predominant groups were blue damselfish, black damselfish, monarch damsel and black tail humbug.
\end{abstract}

KEYWORDS: $\quad$ trap seine net, ornamental fish, air bubbles

\section{PENDAHULUAN}

Ikan hias laut merupakan satu di antara komoditas perikanan yang mempunyai nilai ekonomis penting. Banyaknya ragam warna dan jenis ikan laut yang menghuni perairan karang yang luas di Indonesia menjadikan sumber daya ini penting. Jika ditinjau dari segi potensi dan permintaan pasar, baik di dalam maupun di luar negeri, pengusahaan ikan hias laut masih sangat memungkinkan. Luas perairan karang di Indonesia diperkirakan sekitar $20.000 \mathrm{~km}^{2}$ dengan potensi sumber daya ikan hias laut sebanyak 5.000 ton atau 30-50 juta ekor per tahun, dan diperkirakan tidak kurang dari 400 jenis (Dwiponggo, 1989).

Penangkapan ikan hias dengan jaring lingkar bubu (jarlingbu), dan alat bantu penangkapan misleading ternyata dapat meningkatkan hasil tangkapan jika dibandingkan dengan tanpa memakai misleading (Amin \& Mahiswara, 1990). Pembuatan gelembung udara di dalam air dapat menarik perhatian ikan untuk datang berkumpul, karena selain bentuknya yang menarik perhatian

\footnotetext{
Peneliti pada Balai Penelitian Perikanan Pantai, Maros
} 
ikan, gelembung udara ini juga dapat menaikkan kandungan oksigen terlarut serta mengangkat bahan makan yang tenggelam. Kemampuan gelembung udara untuk menarik ikan dapat dimanfaatkan pada operasi penangkapan ikan hias dengan jaring lingkar bubu.

Akhir-akhir ini banyak nelayan melakukan penangkapan ikan hias dengan cara ilegal yaitu menggunakan bahan beracun (potassium sianida) atau lebih dikenal oleh nelayan sebagai "potas". Potas ini bila disemprotkan akan memabukkan ikan-ikan sehingga ikan-ikan tersebut keluar dari celah-celah karang tempat persembunyiannya Dengan menggunakan serok, ikan yang dalam keadaan mabuk akan mudah ditangkap Penangkapan dengan cara ini menjadi sangat efektif, tapi menimbulkan dampak negatif yang sangat merugikan, karena selain dapat memusnahkan ikan-ikan juga dapat merusak habitatnya. Keadaan ini menjadi sangat tidak menguntungkan di tengah usaha meningkatkan produksi ikan hias guna memenuhi permintaan pasar baik di dalam maupun di luar negeri.

Dalam rangka menunjang usaha peningkatan produksi ikan hias laut maka perlu diupayakan suatu metode penangkapan ikan hias yang efektif dan bersifat ramah lingkungan. Penggunaan jaring lingkar bubu dengan bantuan gelembung udara diduga dapat digunakan untuk menangkap ikan hias, karena gelembung udara diharapkan dapat menarik dan menggiring ikan masuk ke dalam jaring lingkar bubu guna mempermudah penangkapannya. Penelitian ini bertujuan untuk menentukan besaran gelembung udara sebagi alat bantu yang efektif pada penangkapan ikan hias laut dengan jarring lingkar bubu.

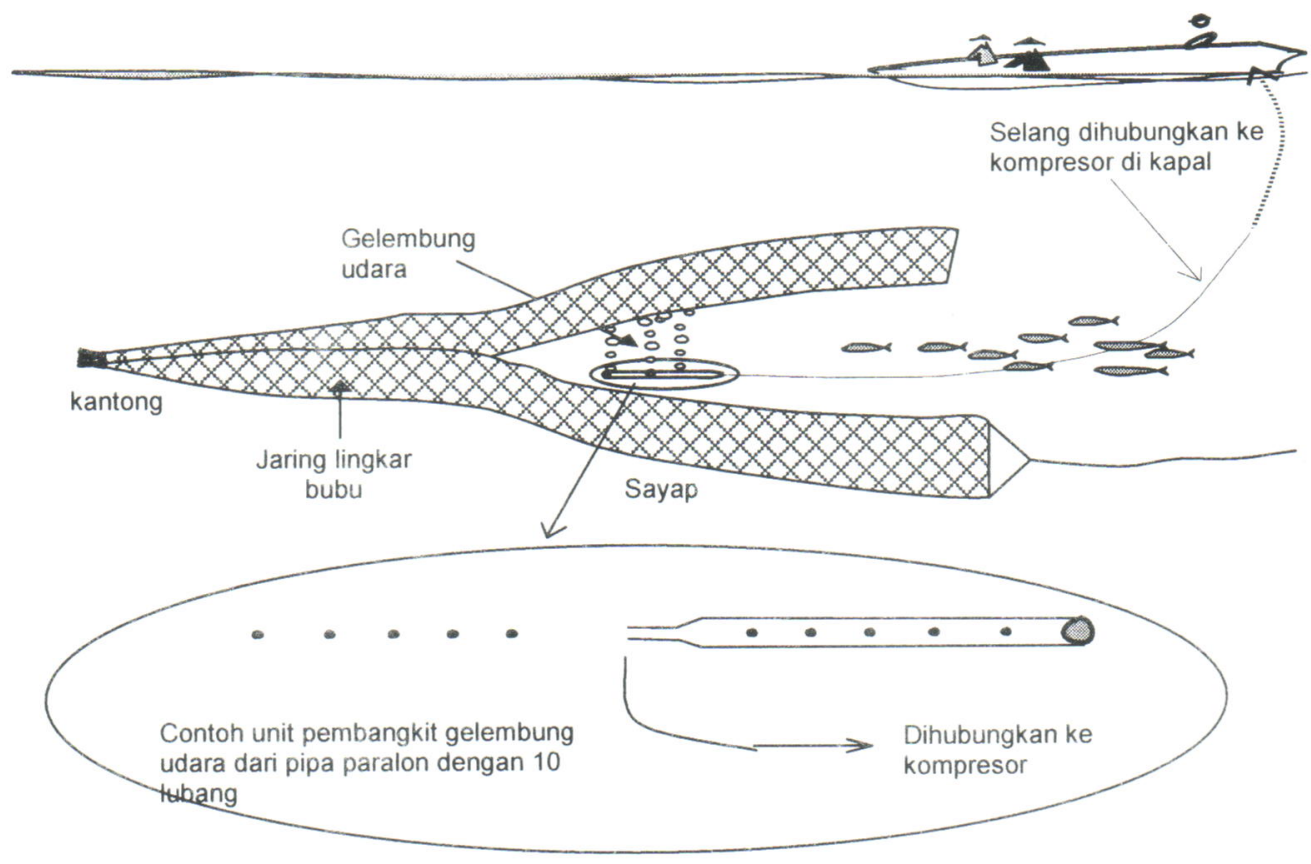

Gambar 1. Ilustrasi posisi unit pembangkit gelembung udara di muka mulut jaring lingkar bubu.

Figure 1. IIlustration of the position of air bubbles generating unit in front of trap seine net.

\section{BAHAN DAN METODE}

Penelitian pengaruh penggunaan gelembung udara sebagai alat bantu jaring lingkar bubu terhadap hasil tangkapan ikan hias dilakukan di perairan sekitar P. Podang-Podang Kabupaten Pangkep Sulawesi Selatan, pada bulan Maret hingga April 1999. Jumlah unit gelembung udara yang dijadikan perlakuan yaitu 5, 10, dan 15 unit. Lama pengopersian jaring lingkar bubu sebelum hauling (pengangkatan) adalah 30 menit dengan selang hauling adalah 60 menit. Jaring lingkar bubu yang digunakan berukuran sayap $17 \mathrm{~m}$ kantong $5 \mathrm{~m}$, dan ijep 1,5 m, dengan bukaan pintu masuk ke bagian kantong 0,4×0,3 m (Gambar 1). Jaring lingkar bubu dioperasikan dengan cara memasang bagian kantong jaring di dasar perairan karang, kemudian kedua sayap jaring direntangkan secara bersamaan membentuk sudut 120 derajat, setelah itu kompressor dijalankan yang akan menghasilkan gelembung udara untuk menarik ikan. Ikan yang tertarik gelembung udara 
tersebut digiring ke arah mulut jaring dan diusahakan agar gerombolan ikan berada dalam cakupan sudut sayap jaring. Kemudian kedua ujung sayap jaring tersebut dipertemukan secara perlahan-lahan sehingga gerombolan ikan yang berada dalam cakupan jaring tertangkap. Pengoperasian jaring dengan menggunakan unit gelembung udara berbeda dilakukan secara bergantian. Sebelum pengopersaian alat, langkah pertama yang dilakukan adalah mencari lokasi perairan karang yang diduga banyak populasi ikan hiasnya. Menurut Pentury (1987), sebelum mengoperasikan alat tangkap langkah pertama yang harus dilakukan adalah mengetahui cara menemukan ikan hias dan cara mempengaruhi tingkah lakunya sehingga dapat meningkatkan efisiensi penangkapan. Tingkah laku ikan merupakan dasar dari metode pengoperasian alat tangkap dan merupakan salah satu kunci keberhasilan suatu operasi penangkapan (Gunarso, 1985).

Parameter yang diamati meliputi: jumlah, jenis, dan komposisi ikan hasil tangkapan. Selain itu dilakukan pula pengamatan terhadap kondisi oseanografi daerah penangkapan yang meliputi: salinitas (diukur menggunakan refraktometer), kecepatan arus (dengan current meter), kedalaman (dengan tali), kecerahan (dengan secchi disk), dan kondisi dasar perairan (secara visual). Untuk mengetahui pengaruh perbedaan perlakuan terhadap hasil tangkapan digunakan uji bertanda Wilcoxon, sedangkan kelayakan kondisi daerah penangkapan dijelaskan secara deskriptif.

\section{HASIL DAN BAHASAN}

\section{Hasil Tangkapan}

Total hasil tangkapan yang diperoleh untuk semua perlakuan selama penelitian (15 kali hauling) sebanyak 1138 ekor, dengan rincian menurut perlakuan sebagai berikut: perlakuan dengan 5 unit gelembung udara 268 ekor atau rata-rata 26 ekor/hauling; untuk perlakuan dengan 10 unit gelembung udara 395 ekor atau rata-rata 26 ekor/hauling, dan untuk 15 unit gelembung udara 475 ekor atau rata-rata 32 ekor/hauling Hasil tangkapan ikan hias berdasarkan perlakuan disajikan pada Tabel 1

Tabel 1. Jumlah hasil tangkapan ikan hias untuk setiap perlakuan

Table 1. Total number of ornamental fish for each treatment

\begin{tabular}{|c|c|c|c|c|c|}
\hline \multirow{2}{*}{ Spesies } & \multicolumn{3}{|c|}{ Perlakuan/Treatment } & \multirow{2}{*}{$\begin{array}{l}\text { Jumlah } \\
\text { Number }\end{array}$} & \multirow{2}{*}{$\begin{array}{l}\text { Persentase }(\%) \\
\text { Persentage }(\%)\end{array}$} \\
\hline & 5 unit & 10 unit & 15 unit & & \\
\hline Abudefduf abdom inalis & 16 & 22 & 42 & 80 & 7,03 \\
\hline Amblighpidodon ternatensis & 15 & 27 & 46 & 88 & 7,73 \\
\hline Amphiprion ocellaris & 1 & 5 & 8 & 14 & 1,23 \\
\hline Chrysiptera unimaculata & 48 & 81 & 32 & 161 & 14.15 \\
\hline Chrysiptera spinger & 53 & 71 & 130 & 254 & 22.31 \\
\hline Chaetodon sp & 0 & 2 & 1 & 3 & 0,26 \\
\hline Damsel pseudochrysopecilus & 32 & 40 & 54 & 126 & 11,07 \\
\hline Damsel fasciatus & 0 & 1 & 2 & 3 & 0,26 \\
\hline Dacylius melanurus & 33 & 30 & 40 & 103 & 9,05 \\
\hline Guatodentex aurolineatus & 10 & 24 & 24 & 58 & 5,09 \\
\hline Helichoeres marginatus & 7 & 11 & 6 & 24 & 2,1 \\
\hline Helichoeres trim aculatus & 14 & 26 & 10 & 50 & 4,39 \\
\hline Helichoeres melanurus & 5 & 10 & 16 & 31 & 2,72 \\
\hline Neoglypidodon oxyodon & 16 & 20 & 33 & 69 & 6.06 \\
\hline Preunas bicualetus & 7 & 4 & 7 & 18 & 1.58 \\
\hline Parupeneus barbarinus & 2 & 2 & 5 & 9 & 0,79 \\
\hline Scarum ovicaps & 1 & 2 & 2 & 5 & 0,43 \\
\hline Thallasoma lunare & 11 & 16 & 14 & 41 & 3,6 \\
\hline Therapon sp & 0 & 1 & 3 & 4 & 0,35 \\
\hline
\end{tabular}

Rincian jumlah total hasil tangkapan ikan hias selama penangkapan pada bulan Maret dan April 1999 disajikan pada Tabel 2. Berdasarkan hasil pengujian non parametik bertanda Wilcoxon ( $T$ ) diperoleh nilai T 105; 94,5; dan 117 untuk setiap perlakuan dengan jumlah unit gelembung udara dari 5, 10, dan 15 unit lubang. Nilai T pada Tabel untuk $n=15$ adalah 25 pada taraf nyata 0,05 . Nilai $T$ ini bila dibandingkan dengan nilai $T$ Tabel, menghasilkan perhitungan nilai $T$ perlakuan dengan jumlah unit gelembung udara 5 dan 10,10 dan 15 , serta 5 dan 15 yang lebih besar, sehingga dapat dikatakan bahwa perlakuan jumlah unit gelembung udara tidak berpengaruh nyata $(P>0,05)$ terhadap hasil tangkapan ikan hias. Jumlah spesies ikan hias yang tertangkap selama penelitian terdiri atas 19 spesies. Empat spesies yang dominan tertangkap adalah Chrysiptera spinger (254 ekor), Chrysiptera unimaculata (161 ekor), Damsel pseudochrysopecillus (126 ekor), dan Dacyllus melanurus (103 ekor). Spesies yang tertangkap paling rendah adalah Therapon sp (4 ekor) dan Damsel fasciatus (3 ekor). Jenis ikan hias yang mempunyai nilai ekonomis penting 
seperti Neoglypidodon oxyodon, Amphiprion ocellaris, Preunas bicuelatus, Damsel fasciatus. masih sedikit yang tertangkap. Jenis ikan hias laut andalan yang banyak digemari baik untuk kebutuhan di dalam maupun di luar negeri (ekspor) seperti famili Pomacanthidae tidak ada yang tertangkap selama penelitian. Hal ini diduga karena penangkapan ikan hias tersebut dilakukan di lokasi perairan yang relatif dangkal (kedalaman 1-1,5 m) dan kondisi perairan terumbu karang tersebut dalam keadaan kritis atau rusak.

Jenis ikan hias Pomacanthidae hidup di perairan karang yang relatif dalam dengan terumbu karang yang masih utuh. Menurut Seaman et al. (1989), kedalaman air merupakan salah satu faktor yang mempengaruhi sebaran dan keberadaan ikan hias pada wilayah terumbu karang. Kehadiran famili ikan hias Pomacanthidae tersebut dapat dijadikan sebagai salah satu indikator kondisi terumbu karang perairan setempat (Edrus et al., 1996).

Tabel 2 memperlihatkan rata-rata hasil tangkapan ikan hias per hauling selama bulan
Maret tidak berbeda nyata dengan hasil tangkapan pada bulan April. Hal ini disebabkan bulan Maret dan April berada pada musim yang sama yaitu musim penghujan (barat), sehingga tidak mempengaruhi hasil tangkapan ikan hias secara signifikan.

Di perairan pantai barat Sulawesi Selatan khususnya di perairan P. Podang-Podang sangat sulit untuk mendapatkan kawasan terumbu karang dalam keadaan utuh. Hal ini mengindikasikan bahwa jumlah sumber daya ikan hias yang bernilai ekonomis penting semakin menurun. Rendahnya hasil tangkapan ikan hias baik jumlah individu maupun keragaman jenisnya diperkirakan berkaitan dengan kondisi terumbu karang pada lokasi penangkapan yang mengalami degradasi dan dalam kondisi kritis dengan jumlah rata-rata tutupan karang hidup tinggal $27,8 \%$ nya (Wagiyo et al., 1998). Penurunan kondisi terumbu karang dari sangat baik (penutupannya 75-100\%) ke kondisi rusak (penutupannya 25-49,9\%) menyebabkan penurunan kepadatan ikan karang termasuk ikan hias sebesar 61\% (Wagiyo \& Prahoro. 1994). Hal ini diperkuat oleh pernyataan

Tabel 2. Jumlah hauling dan hasil tangkapan ikan hias pada setiap perlakuan, pada bulan Maret dan April 1999

Table 2. Number of hualing and catch of ornamental fish in each treatment of March and April 1999

\begin{tabular}{|c|c|c|c|}
\hline \multirow{2}{*}{$\begin{array}{l}\text { Perlakuan jumlah unit } \\
\text { pembangkit gelembung/Teatment } \\
\text { of bubbles generating hole units }\end{array}$} & \multicolumn{2}{|c|}{ Waktu penangkapan/Operation time } & \multirow[b]{2}{*}{ Jumlah/Total } \\
\hline & $\begin{array}{c}\text { Maret/March } \\
\text { (7 hauling) }\end{array}$ & $\begin{array}{l}\text { April/April } \\
\text { (8 hauling) }\end{array}$ & \\
\hline 5 unit & $\begin{array}{c}144 \text { ekor } \\
\text { (16 ekor/hauling) }\end{array}$ & $\begin{array}{c}154 \text { ekor } \\
\text { (18 ekor/hauling) }\end{array}$ & 268 ekor \\
\hline 10 unit & $\begin{array}{c}183 \text { ekor } \\
\text { (26 ekor/hauling) }\end{array}$ & $\begin{array}{c}212 \text { ekor } \\
\text { (27 ekor/hauling) }\end{array}$ & 395 ekor \\
\hline 15 unit & $\begin{array}{c}220 \text { ekor } \\
\text { (31 ekor/hauling) }\end{array}$ & $\begin{array}{c}255 \text { ekor } \\
\text { (32 ekor/hauling) }\end{array}$ & 475 ekor \\
\hline Total & 517 & 621 & 1138 \\
\hline
\end{tabular}

Tabel 3. Kondisi oseanografi perairan di sekitar lokasi penangkapan

Table 3. Oceanographycal condition of fishing location waters

\begin{tabular}{lc}
\multicolumn{1}{c}{ Variabel/Variable } & Nilai/Value \\
\hline Salinitas $(\mathrm{ppt})$ & $31-34$ \\
$\mathrm{PH}$ & $7,53-7,95$ \\
$\mathrm{BOT} / \mathrm{TOM}(\mathrm{ppm})$ & $3,17-34,82$ \\
$\mathrm{NO}_{2}(\mathrm{ppm})$ & $0,0136-0,0378$ \\
$\mathrm{NO}_{3}(\mathrm{ppm})$ & $\mathrm{ttd}$ \\
$\mathrm{NH}_{4}(\mathrm{ppm})$ & $0,0679-0,1185$ \\
$\mathrm{PO}_{4}(\mathrm{ppm})$ & $\mathrm{ttd}-0,0209$ \\
$\mathrm{Suhu} /$ Temperature $\left({ }^{0} \mathrm{C}\right)$ & $29-33$ \\
Kedalaman/Water depth $(\mathrm{m})$ & $0,0-2,0$ \\
Kecepatan arus/Current speed (cm/det) & $32,5-45,31$ \\
Kecerahan/Transparancy $(\mathrm{m})$ & $100(\%)$ \\
Dasar/Bottom & Pasir karang \\
Kondisi karang/Coral condition & Kritis-rusak \\
Rata-rata tutupan karang/Coral coverage (\%) & 27,8 \\
\hline
\end{tabular}


Hutomo et al., 1985, bahwa ada hubungan positip antara kerusakan karang dengan potensi ikan hias di suatu perairan. kondisi oseanografi perairan pada lokasi penangkapan selama penelitian ditunjukkan dalam Tabel 3.

Kondisi oseanografi di lokasi penelitian masih layak untuk kehidupan ikan hias. Secara umum kondisi terumbu karang sudah mengalami degradasi, dengan rata-rata tutupan karang hidup tinggal sebesar 27,8 \%nya, sehingga ikan hias yang tertangkap didominasi oleh jenis-jenis ikan hias yang toleran terhadap jenis karang yang sudah rusak, seperti Abudefauf, Damsel, Apogon, Pilo, dan Zebra. Sedangkan ikan hias yang mempunyai nilai ekonomis tinggi yang tergolong dalam famili Pomacanthidae, seperti jenis ikan injel, piyama, dan kambing-kambing (Angelfish) tidak tertangkap selama pelaksanaan penelitian.

\section{KESIMPULAN}

Hasil tangkapan ikan hias menggunakan jaring lingkar bubu dengan perlakuan jumlah unit gelembung udara yang berbeda tidak menunjukkan perbedaan nyata.

$\begin{aligned} & \text { Jenis-jenis ikan Chrysiptera r speringer, } \\ & \text { Chrysiptera unimaculata, }\end{aligned}$
pseudochsopecilus, dan Dacillus melanurus
merupakan hasil tangkapan jaring lingkar bubu
yang dominan.

\section{DAFTAR PUSTAKA}

Amin M. \& Mahiswara. 1990. Jaring lingkar bubu sebagai suatu alternatif alat tangkap ikan hias. Jurnal Penelitian Perikanan Laut 54: 97--106.
Pentury, P. 1987. Studi tentang respon ikan terhadap tegangan listrik. Fakultas Perikanan dan IImu Kelautan IPB. Bogor. (tidak diterbitkan)

Dwiponggo, A. 1989. Prospek perikanan bagi keperluan domestik dan ekspor non migas. (makalah tidak dipublikasikan)

Edrus, I. M., A. Ronny Syam, \& Suprapto. 1996. Penelitian komunitas ikan pada terumbu karang buatan di perairan Dusun Jemeluk. Kabupaten Amlapura. Bali. Jurnal Penelitian Perikanan Laut. Jakarta 2(1):1-14.

Hutomo,M., Suharsono, \& S. Martosewejo. 1985. Ikan hias indonesia dan kelestarian terumbu karang. makalah pada sarasehan ikan hias laut Indonesia. Jakarta 12 Oktober 1985. 25 hal.

Seaman, W. Jr., W. J. Linberg, C. R. Gilbert, T.K. Frazer. 1989. Fish habitat provided by absolute petroleum plat forms of Shouthern Florida. Bull. Mar. Sci., 44(2): 10-14.

Wagiyo, K., Suprapto, \& H. Mubarak. 1998 Kondisi dan struktur terumbu karang di perairan barat Sulawesi Selatan. Jurnal Penelitian Perikanan Indonesia, 4(2): 1--7.

Wagiyo, K. \& P. Prahoro. 1994. Pengaruh kondisi terumbu karang terhadap komunitas ikan hias di Kep. Karimunjawa. Jurnal Penelitian Perikanan Indonesia, 92: 27--36.

Gunarso, W. 1985. Suatu Pengantar tentang fish behavior dalam hubunganya dengan Fishing Techniques dan Fishing Tactics. Fakultas Perikanan dan IImu Kelautan IPB. Bogor 
Abdul Malik Tangko, Abdul Mansyur, dan Daud Pongsapan

\section{Lampiran 1}

Appendix 1

Tabel 1. Analisis data hasil tangkapan antara perlakuan 5 unit dan 10 unit lubang pembangkit gelembung udara

Table 1. Catch data analysis between of 5 units and 10 units of air bubbles

\begin{tabular}{lcccc}
\hline $\begin{array}{l}\text { Jumlah/Hauling } \\
\text { number }\end{array}$ & \multicolumn{2}{c}{ Perlakuan/Treatment } & Beda (Y1-X1) & Pangkat beda \\
\cline { 2 - 4 } 1 & $\mathbf{5}$ unit (XI) & $\mathbf{1 0}$ unit (Y1) & 18 & +11 \\
2 & 7 & 23 & +15 & +13 \\
3 & 8 & 14 & -6 & -5 \\
4 & 20 & 36 & +9 & +7 \\
5 & 27 & 42 & +30 & +15 \\
6 & 12 & 23 & +2 & -2 \\
7 & 25 & 27 & -2 & $+11,5$ \\
8 & 15 & 24 & +11 & +2 \\
9 & 26 & 26 & -5 & $+9,5$ \\
10 & 15 & 25 & -2 & -2 \\
11 & 30 & 11 & +12 & $+11,5$ \\
12 & 13 & 30 & +10 & +8 \\
13 & 18 & 27 & +27 & +14 \\
14 & 17 & 42 & +7 & +6 \\
15 & 15 & 27 & & \\
\hline Jumlah & 20 & $\mathbf{3 9 5}$ & & \\
\hline
\end{tabular}

Nilai positip/Positive values

\section{$9,5+13+7+15+11,5+9,5+11,5+8+14+6=105$}

Nilai negatif/Negative values

\section{$5+2+2+4+2=15$}

Untuk $n=15$ diperoleh $T_{0,05}=25$, oleh karena nilai $T$ hitung $=105$ lebih besar dari pada nilai $T$ tabel $=25$, maka diterima Ho ini berarti bahwa perlakuan 5 unit gelembung udara tidak berbeda nyata dengan perlakuan 10 unit gelembung udara/For $n=15$; calculated $T_{0,05}=25$; since calculated $T=105$ is greater than table $T=25$ than Ho is acceptable. Thus, 5 holes of air bubbles generating unit is no significan Hy different with that of 10 holes. 


\section{Lampiran 2}

Appendix 2

Tabel 2. Analisis data hasil tangkapan antara perlakuan 5 unit dan 15 unit lubang pembangkit gelembung udara

Table 2. Catch data analysis between of 5 units and 15 units of air bubbles

\begin{tabular}{lcccc}
\hline \multirow{2}{*}{$\begin{array}{c}\text { Jumlah/Hauling } \\
\text { number }\end{array}$} & \multicolumn{2}{c}{ Perlakuan/Treatment } & Beda (Y1-X1) & Pangkat beda \\
\cline { 2 - 3 } & $\mathbf{5}$ unit (XI) & $\mathbf{1 5}$ unit (Y1) & +39 & +15 \\
2 & 7 & 46 & +13 & +6 \\
3 & 8 & 21 & +2 & +2 \\
4 & 20 & 22 & +19 & +12 \\
5 & 27 & 46 & +29 & +14 \\
6 & 12 & 37 & 0 & +1 \\
7 & 25 & 25 & +8 & +4 \\
8 & 15 & 23 & -2 & +5 \\
9 & 26 & 36 & +10 & +13 \\
10 & 15 & 35 & 20 & -3 \\
11 & 30 & 27 & -3 & +9 \\
12 & 13 & 28 & +15 & +9 \\
13 & 18 & 33 & +15 & +9 \\
14 & 17 & 32 & +15 & +11 \\
15 & 15 & 32 & +12 & +7 \\
\hline Jumlah & 20 & 32 & & \\
\hline
\end{tabular}

Nilai positip/Positive values $15+6+2+12+14+1+4+5+13+9+9+9+11+7=117$

Nilai negatif/Negative values : 3

Untuk $n=15$ diperoleh $T_{0,05}=25$, oleh karena nilai $T$ hitung $=117$ lebih besar dari pada nilai $T$ tabel $=25$, maka diterima Ho ini berarti bahwa perlakuan 5 unit gelembung udara tidak berbeda nyata dengan perlakuan 15 unit gelembung udara/For $n=15$; calculated $T_{0,05}=25$; since calculated $T=117$ is greater than table $T=25$ than Ho is acceptable. Thus, 5 holes of air bubbles generating unit is no significan Hy different with that of 15 holes. 
Abdul Malik Tangko, Abdul Mansyur, dan Daud Pongsapan

\section{Lampiran 3}

Appendix 3

Tabel 3. Analisis data hasil tangkapan antara perlakuan 10 unit dan 15 unit lubang pembangkit gelembung udara

Table 3. Catch data analysis between of 10 units and 15 units of air bubbles

\begin{tabular}{lcccc}
\hline Jumlah/Hauling & \multicolumn{2}{c}{ Perlakuan/Treatment } & Beda (Y1-X1) & Pangkat beda \\
\cline { 2 - 3 } number & $\mathbf{1 0}$ unit $(\mathbf{X I})$ & $\mathbf{1 5}$ unit (Y1) & +28 & +15 \\
\hline 1 & 18 & 46 & -2 & -2 \\
2 & 23 & 21 & +8 & +9 \\
3 & 14 & 22 & +10 & $+11,5$ \\
4 & 36 & 46 & -5 & -7 \\
5 & 42 & 37 & +2 & +2 \\
6 & 23 & 25 & +4 & -5 \\
7 & 27 & 23 & +12 & +13 \\
8 & 24 & 36 & +10 \\
9 & 26 & 35 & +2 & +2 \\
10 & 25 & 27 & +17 & +14 \\
11 & 11 & 28 & +4 \\
12 & 30 & 33 & +5 & +7 \\
13 & 27 & 32 & -10 & $+1,5$ \\
14 & 42 & 32 & +5 & +7 \\
15 & 27 & 32 & & \\
\hline
\end{tabular}

Nilai positip/Positive values $: 15+9+11,5+2+13+10+2+14+4+6+7=94,5$

Nilai negatif/Negative values $: 2+7+5+11,5=25,5$

Untuk $n=15$ diperoleh $T_{0,05}=25$, oleh karena nilai $T$ hitung $=94,5$ lebih besar dari pada nilai $T$ tabel $=25$, maka diterima $\mathrm{Ho}$ ini berarti bahwa perlakuan 10 unit gelembung udara tidak berbeda nyata dengan perlakuan 10 unit gelembung udara/For $n=15$; calculated $T_{0,05}=25$; since calculated $T=94,5$ is greater than table $T=25$ than Ho is acceptable. Thus, 10 holes of air bubbles generating unit is no significan Hy different with that of 15 holes. 